\title{
O FOTOJORNALISMO DOS PERIÓDICOS CORREIO DA MANHÃ E TRIBUNA DO NORTE E AS MARCAS CULTURAIS DAS FESTAS POPULARES DO MÊS DE JUNHO
}

\author{
Élmano Ricarte de Azevêdo Souza \\ Universidade Federal do Rio Grande do Norte, Brasil \\ Itamar de Morais Nobre \\ Universidade Federal do Rio Grande do Norte, Brasil
}

\begin{abstract}
Resumo: Investiga-se e analisa-se as marcas e a produção de sentido sobre a cultura popular, em homenagem aos santos católicos do mês de junho: Santo Antônio, São João e São Pedro (celebrados, respectivamente, nos dias 13, 24 e 29) nas fotografias jornalísticas dos periódicos Tribuna do Norte (Natal, Rio Grande do Norte, Brasil) e Correio da Manhã (Lisboa, Portugal), publicadas no mês de junho de 2012. Toma-se como base teórica e metodológica a Fotocartografia Sociocultural e a Folkcomunicação. Pressupõe-se que tais imagens possuem conteúdo e significados representacionais das manifestações e identidades culturais populares das festas de junho e dos santos católicos daquele mês. Busca-se identificar e analisar como as manifestações e culturas populares foram apropriadas pela mídia fotojornalística.
\end{abstract}

Palavras-chave: Fotografia Jornalística; Manifestações Culturais; Festas de Junho; Fotocartografia Sociocultural; Folkcomunicação.

\section{Introdução}

O estudo foi concentrado nas fotos produzidas e publicadas pelos jornais Tribuna do Norte, com sede no município de Natal, Rio Grande do Norte (nordeste do Brasil), e Correio da Manhã, com sede na cidade de Lisboa, Portugal. O período analisado corresponde a todo mês de junho de 2012, no qual são realizadas as manifestações culturais populares voltadas para as homenagens aos santos católicos Santo Antônio, São João e São Pedro ${ }^{1}$ (celebrados, respectivamente, nos dias 13, 24 e 29 de junho).

\footnotetext{
${ }^{1}$ Santo Antônio é festejado no dia 13 de junho. Santo Antônio também é conhecido como Santo Antônio de Pádua ou Santo Antônio de Lisboa. Nasceu em Lisboa, no dia 15 de agosto de 1195, e morreu em Pádua, em 13 de junho de 1231. Foi monge da Ordem Franciscana e doutor da Igreja. É o santo patrono de Portugal e carrega o menino Jesus em seus braços. [...] São João Batista, o anunciador de Cristo - a comemoração de seu nascimento foi fixada em 24 de junho. Quando viu ao longe a fumaça da fogueira, Maria soube que sua prima Isabel dera à luz naquele dia um menino, chamado João, que não só preparou a vinda do Messias como o batizou, nas águas do rio Jordão. [...] São Pedro - é representado nos Evangelhos como o primeiro apóstolo. Nos momentos decisivos, em que a missão de Cristo envolve crise, é ele o porta-voz dos apóstolos. O santo é comemorado no dia 29, data da sua morte. É o guardião das portas do céu e o comandante das chuvas. Nasceu em Betsaida, Galiléia. Pescador de Carfanaum, tornou-se discípulo de Jesus, que o escolheu como líder do colégio apostólico (Lucena Filho, 2012, p. 46-48).
} 
Após a coleta de todas as edições dos jornais mencionados no período relacionado, selecionaram-se reportagens jornalísticas que estejam claramente relacionadas ao objetivo-geral pretendido: investigar e analisar como é construído o significado das marcas culturais sobre as manifestações populares em homenagem aos santos católicos do mês de junho nas fotografias jornalísticas dos periódicos Tribuna do Norte e Correio da Manhã no mês de junho de 2012. A atenção direcionou-se para os aspectos e elementos emblemáticos da cultura popular daquelas cidades presentes nas fotografias jornalísticas.

Como aporte teórico e metodológico, utilizou-se o Método da Fotocartografia Sociocultural defendido por Nobre (2011), o qual descreve e analisa o processo de interpretação e percepção sociocultural das comunidades pertencentes à Reserva de Desenvolvimento Sustentável Estadual Ponta do Tubarão no estado do Rio Grande do Norte (nordeste brasileiro) a partir da fotografia, utilizando-a como uma carta, um mapa sociocultural. De forma sintética, a Fotocartografia Sociocultural seria descrita como a união dentre os conceitos teóricos e técnicos da fotografia e da cartografia, resultando em um novo método, cujo propósito é mapeamento pelo ato fotográfico, aliado às técnicas de: observação; entrevistas; pesquisa documental e pesquisa bibliográfica.

Em sua investigação, Nobre (2011) é o produtor das imagens. Todavia, seu método pode ser aplicado à leitura de fotografias jornalísticas, buscando aspectos socioculturais que representem os modos de vida de uma determinada comunidade como a religiosidade, o lazer e saberes tradicionais, acrescentando-se aqui nesta investigação, todavia uma nova categoria: economia (a partir do turismo, agricultura e pesca).

Em cada uma das fotografias jornalísticas selecionadas, o significado de sua representação na cultura popular não está diretamente revelada ao leitor, com a leitura daquela imagem impressa. Nesse aspecto, a Folkcomunicação auxilia a identificar como a mensagem popular e seus modos de vida estão presentes no cenário sociocultural local, passando a construir sentido àquela imagem, revelando aspectos que podem estar ocultos no quadro fotográfico como o saber tradicional, a devoção, as simpatias e heranças de eras pagãs agregadas ao catolicismo durante os séculos.

A fotografia jornalística, enquanto ofício, é encarada como mediação entre o mundo e o leitor do periódico, buscando trazer uma parcialidade desta cultura em honra aos santos católicos do mês de junho. Sendo assim, pode reportar manifestações culturais presentes em uma sociedade. 
Propõe-se, portanto, uma compreensão de como a cultura popular, com seus modos de vida e comunicação do povo sobre si, pode ser codificada pelos autores da fotografia jornalística. E, ao realizar-se uma leitura destas imagens, entende-se o ser humano como "dotado da capacidade de organizar a sua cultura e a sua sociedade a partir da produção de conhecimento, por meio da linguagem e dos modos de vida" (Nobre, 2011, p. 50). Por sua vez a cultura é em si um ingrediente social importante para a organização de uma sociedade, porque é, de acordo com Flusser (s.d., p. 3), um "conjunto de fenômenos ligados entre si 'simbolicamente", sendo um mapa simbólico como discute Nobre (2011), vindo a auxiliar na localização do homem no mundo, com a sua leitura. Ou seja, a fotografia no jornalismo, ao tratar sobre a cultura popular, pode trazer representações dos fenômenos de uma cultura local e ser um signo sobre aquela cultura.

\section{As fotografias do jornal Tribuna do Norte}

Como herança da tradição pré-cristã, as sociedades de matriz cultural católica, como parte do Brasil e Portugal, mantêm traços dos festejos populares em reverência aos seus santos, na qual há uma hibridização entre o que é dito como católico e tratado como pagão. Uma delas é a população da região metropolitana, mas também de toda capital do município de Natal, com cerca de 1 milhão e 400 mil habitantes (Brasil, 2010), capital do estado do Rio Grande do Norte (nordeste brasileiro). Na região metropolitana do município de Natal, as principais festas são em homenagem a São João e ocorrem em bairros populares como Cidade da Esperança e Felipe Camarão (Zona Oeste), Mãe Luiza, Rocas e Santos Reis (Zona Leste), Alecrim, Quintas e Cidade Satélite (Zona Sul e Centro) e Panatis, Parque das Dunas, Igapó e Santa Catarina (Zona Norte), e também nas cidades da grande Natal como São Gonçalo do Amarante, Extremoz, Parnamirim, Ceará-Mirim, Macaíba, São José de Mipibu, Nísia Floresta, Monte Alegre e Vera Cruz. São em sua maioria festas com procissões e carreatas com fiéis pelas ruas das cidades, feiras de comidas típicas da região nordeste a base de milho, como canjica, mungunzá e pamonha, arraias em vias públicas, quadrilhas juninas e concursos de quadrilhas matutas e estilizadas, realizados pelas emissoras InterTV Cabugi e TV Ponta Negra, filiadas no Rio Grande do Norte da Rede Globo e do $S B T$, respectivamente.

Quando estas festas e manifestações populares foram impressas nas páginas do jornal Tribuna do Norte, no mês de junho de 2012, foram publicadas 10 reportagens e três chamadas sobre o tema em análise. 
Para efeito de análise, recortou-se o material coletado e foram selecionadas duas dessas reportagens e manchetes para investigar as suas fotografias por serem as mais emblemáticas sobre a cultura popular, uma vez que trazem ao leitor uma marca cultural a qual poder ser classificada como a mais representativa no imaginário coletivo. A primeira marca a ser analisada foi a fotografia da manchete publicada no dia 10 de junho de 2012 (Santo, 2012):

Imagem 1: "Comemorações e simpatias em torno de Santo Antônio - padroeiro dos namorados - abrem as festas juninas, tradição nordestina com raízes na antiguidade” (Santo, 2012).

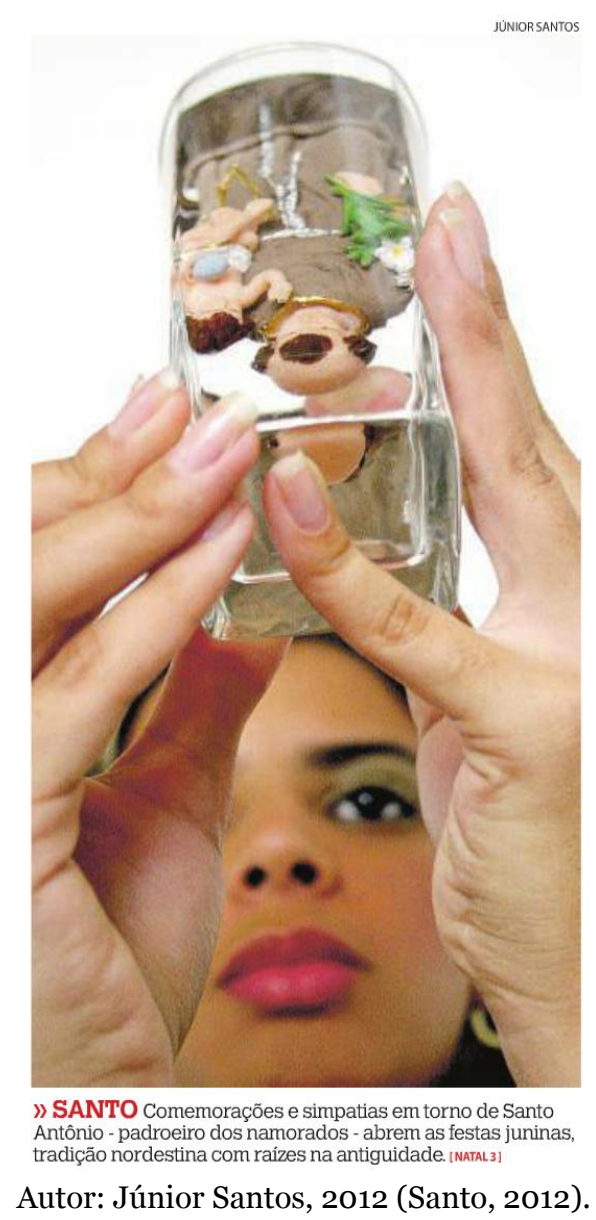

A imagem 1 do fotógrafo Júnior Santos mostra, em cores, uma jovem olhando a imagem de Santo Antônio virada de cabeça para baixo. A foto está com a jovem em segundo plano sem foco e com um enquadramento em plano detalhe para mãos dela, já em primeiro plano com foco, há o santo. A fotografia jornalística foi realizada com ângulo contrapicado. Nesta imagem, a escolha desse ângulo, com o uso deste foco apenas na mão e na imagem do santo, além da composição com o desfoque para o rosto da devota e enquadramento de seus olhos atentos proporcionam um destaque para o ato da simpatia com o fato do santo está ao inverso. 
A imagem 1 representa uma simpatia. O significado deste termo popular no Brasil é apontado por Cascudo (2000, p. 637) como "[...] um conjunto de atos e palavras preestabelecidas, repetidos sem qualquer alteração, a não ser o nome do interessado”, sendo um ritual que "mobiliza as forças e poderes ocultos para satisfazer nossos desejos”. O ritual da simpatia não é uma prática prescrita pela Igreja Católica, mas de origem na cultura do povo. No caso da imagem 1, constata-se a simpatia, normalmente, realizada por mulheres solteiras, nos festejos antoninos, que pedem ao Santo Antônio, conhecido popularmente no Brasil e em Portugal, como santo casamenteiro. As mulheres que praticam este ato solicitam ao santo "arranjar" um marido. É uma das simpatias mais populares por todo o Brasil, em que Santo Antônio é colocado de cabeça para baixo para que atenda ao pedido. As devotas colocam o santo na posição que mostra a imagem 01, fazem o seu pedido e o deixam assim até que ele "encontre" um noivo para casar em seu dia, celebrado em 13 de junho.

Cascudo (1985) também relata que outros atos são realizados durante o mesmo período de festas no Brasil com a imagem deste santo, desde mergulhá-lo em um balde com água para pedir que chuva venha ou colocá-lo próximo a uma fonte de luz para acalmar a força do sol em tempos de seca ou poucas chuvas.

Os maus tratos a Santo Antônio não são públicos. Pertencem aos cultos pessoais. Põem o santo dentro d'água amarrado, para ser retirado quando do implemento da promessa, arrancam-lhe do braço o Menino Jesus, colocam-no de cabeça para baixo dentro do resto d'água do açude semi-esgotado, deixam-no em cima do telhado, exposto ao sol ardente para que melhor sinta o horror da sede e providencie chuvas (Cascudo, 1985, p. 52).

Ainda segundo Cascudo (1985), essa tradição popular de maus-tratos ao Santo Antônio é uma herança grega e romana praticada com as imagens dos deuses da guerra e da fortuna.

Logo, o sentido da imagem 1, de uma forma mais aprofundada quando observamos estas nuances na cultura popular e os significados cuja cena pode trazer implicitamente, é de um saber tradicional, composto por uma herança trazida de geração em geração.

No dia 22 de junho de 2012, o caderno Fim de Semana trouxe uma manchete (imagem 2) que remete a duas reportagens. A fotografia jornalística mostra uma quadrilha junina em formação de coreografia. A imagem 2 percorre quase $90 \%$ de toda a página ${ }^{2}$

\footnotetext{
${ }^{2}$ A página de tal caderno, no jornal Tribuna do Norte, tem $30 \mathrm{~cm}$ x $20 \mathrm{~cm}$, sendo uma edição apenas para o fim-de-semana.
} 
para chamar o leitor para o conteúdo seguinte dentro do suplemento. O fotógrafo Aldair Dantas optou por um ângulo contrapicado, enquadrando as bandeirolas, ao fundo, buscando dar ênfase na coreografia e no cenário dispostos na cena retratada, revelando a alegria presente naquele ambiente, a partir dos elementos que são visíveis na imagem. A quadrilha representada na imagem 2 faz parte das festas que acontecem na rua São João, no bairro de Lagoa Seca, no município de Natal, Rio Grande do Norte, Brasil, como parte das comemorações em honra ao santo primo de Jesus Cristo.

Imagem 2: "LAMPEJOS DE SÃO JOÃO: Fim de Semana visita tradicional da rua São João, em Lagoa Seca (...)" (Vivane, 2012, p. o6).

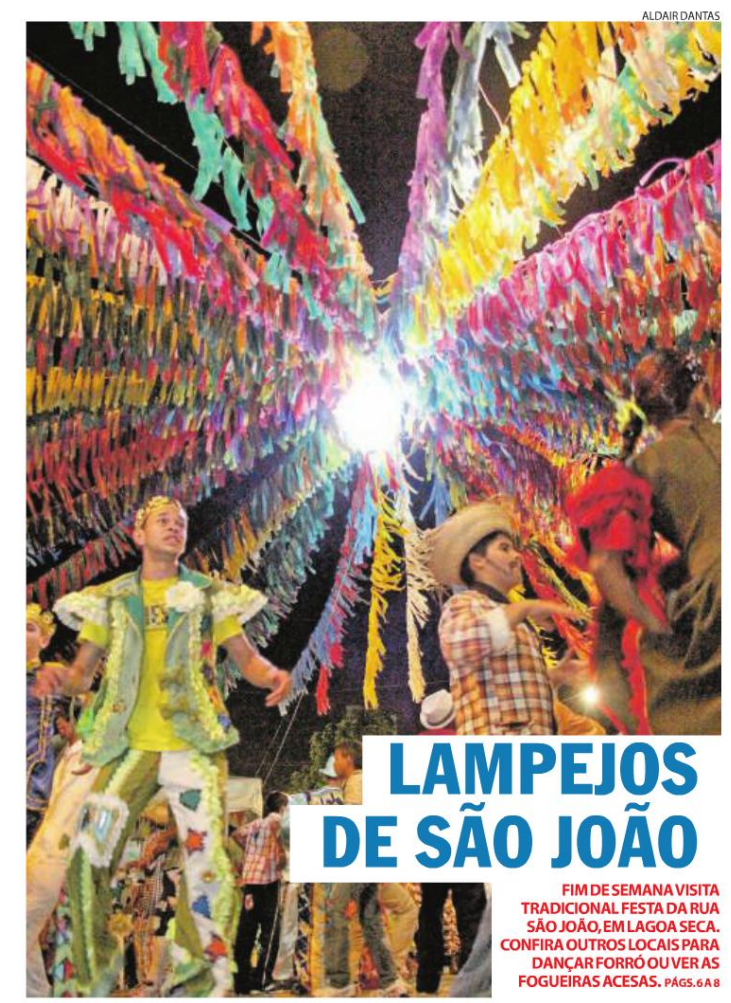

Autor: Aldair Dantas, sem data (Vivane, 2012, p. 06).

A rua é transformada em um arraial, um lugar onde se unem os devotos para celebrar e prestar honras a São João. Vários elementos simbólicos fazem parte desse cenário e um deles aparece em destaque com muitas cores. Tratam-se das bandeirolas com várias pequenas bandeiras ou fitas coloridas. A presença delas, nesta festa, remete e significa, segundo Cascudo (1985), a um antigo costume de purificação por meio da água. Os devotos, a cada ano, realizam a "lavagem do santo" nos rios próximos às capelas em que o santo do dia é padroeiro. Como representação desse ato, as bandeirinhas eram postas molhadas de um lado para o outro nas ruas ou no arraial para purificar os que passassem por baixo delas. Dessa forma, todos que passassem pelo espaço da festa podiam se sentir abençoados pelo santo como anteriormente acreditavam estar ao banhá-lo nas águas do rio. Por esta razão, ao escolher o ângulo contrapicado na 
imagem 02, o fotógrafo não apenas capta os componentes da coreografia e seus trajes, mas também a bandeirola como elemento importante para atribuir sentido àquela cena, remetendo àquele conhecimento anterior da bênção pela água. Sendo assim, a imagem 02 significa o local abençoado pelo ato de fé dos devotos, um lugar em que todos celebram em família e amigos.

\section{As fotografias do jornal Correio da Manhã}

$\mathrm{Na}$ área metropolitana da cidade de Lisboa, as principais festas são em homenagem a Santo Antônio e ocorrem nas áreas turísticas, como na praça Restauradores, na região do cais, no pavilhão Atlântico e ainda nos municípios da Área Metropolitana de Lisboa: Azambuja, Mafra, Amadora, Cascais, Lisboa, Loures, Odivelas, Oeiras, Sintra, Vila Franca de Xira, Alcochete, Almada, Barreiro, Moita, Montijo, Palmela, Seixal, Sesimbra e Setúbal. São em sua maioria, Casamentos de Santo António na Catedral da Sé na cidade, feiras populares como a de Festas das Sardinhas, apresentações ao ar livre em praças e logradouros públicos com artistas locais e convidados e as Marchas Populares. Essas últimas reúnem os habitantes das freguesias para desfilarem e se apresentarem com trajes estilizados ao som de marchas com temas de cultura local ou elementos naturais da região lisboeta como o fado, personalidades ou fauna e flora locais.

Ao serem retratadas estas festas e manifestações populares a partir do jornalismo impresso nas edições do Correio da Manhã, no mês de junho de 2012 publicaram-se 28 inserções jornalísticas (que variam entre notas e reportagens) reportagens e duas chamadas sobre o tema em análise.

A título de ilustração para este artigo, foram selecionadas apenas três das fotografias, nas quais se aplicaram a metodologia e teoria escolhidas, buscando revelar o conhecimento e saber tradicional e religioso e também os aspectos socioculturais de cada comunidade. Por sua vez, estas foram escolhidas por retratarem com maior força o tema escolhido para análise dentro da cultura popular local.

O ponto alto das festas populares de junho em Lisboa ocorre na véspera do dia de Santo Antônio, homenageado em 13 de junho, quando acontece o evento "Casamentos de Santo Antônio”, realizado na Sé de Lisboa, localizada no bairro da Mouraria. Esta Igreja traz um simbolismo para os católicos daquela cidade, pois foi a Igreja na qual o santo local foi batizado, recebeu a primeira comunhão, e onde ele realizou alguns milagres, como quando fazia parte do coral e, sentindo-se mal, em meio a uma canção, sustentou a sua mão na parede de pedra, deixando a sua forma lá e, em seguida, passando a aparecer ao lado do coral. Este episódio ficou conhecido como Milagre da Bilocação (estar em dois lugares ao mesmo tempo). É importante ressaltar ainda que: 
“(...) Santo Antônio é muito acariciado pelos lisboetas. É considerado protetor das almas do purgatório, defensor dos animais, curandeiro, advogado dos objetos perdidos, além de assumir no imaginário popular um propiciador dos bons casamentos (...)" (Lucena Filho, 2012, p. 102).

Sendo assim, o Santo nascido em Lisboa é o principal personagem desta festa e anima as ruas da cidade.

Na análise do jornal Correio da Manhã, apresentam-se no dia 13 de junho de 2012 as seguintes reportagens que preenchem as páginas 26 e 27 do caderno Especial: "Noivos juram amor eterno" e "Sardinha no pão por 1,5 euros". A primeira reportagem traz três fotografias sobre o "Casamentos de Santo Antônio". Escolheu-se a imagem o3 para representar esta reportagem, por trazer o maior número de noivos. Em plano geral de pessoas, ocupando parte das duas páginas, a fotografia mostra 11 casais selecionados pela Câmara Municipal de Lisboa para se casarem neste dia, véspera de Santo Antônio, naquela Igreja. A fotografia significa, com este enquadramento, a quantidade de casamentos realizados e da realização dos mesmos na Sé de Lisboa. Esta imagem pode representar um vasto número de casais que escolhem a data para se casarem justamente neste dia por acreditarem na intercessão do Santo Antônio para sua concretização. Além disso, a fotografia vem testificar esta tradição popular relacionada ao santo de Lisboa, como uma prova de seus milagres intermediados junto a Deus.

Imagem 3: "Um momento único com os 11 casais que deram o nó na Sé de Lisboa. No final, centenas de populares aguardavam" (Carvalho, 2012, p. 27).

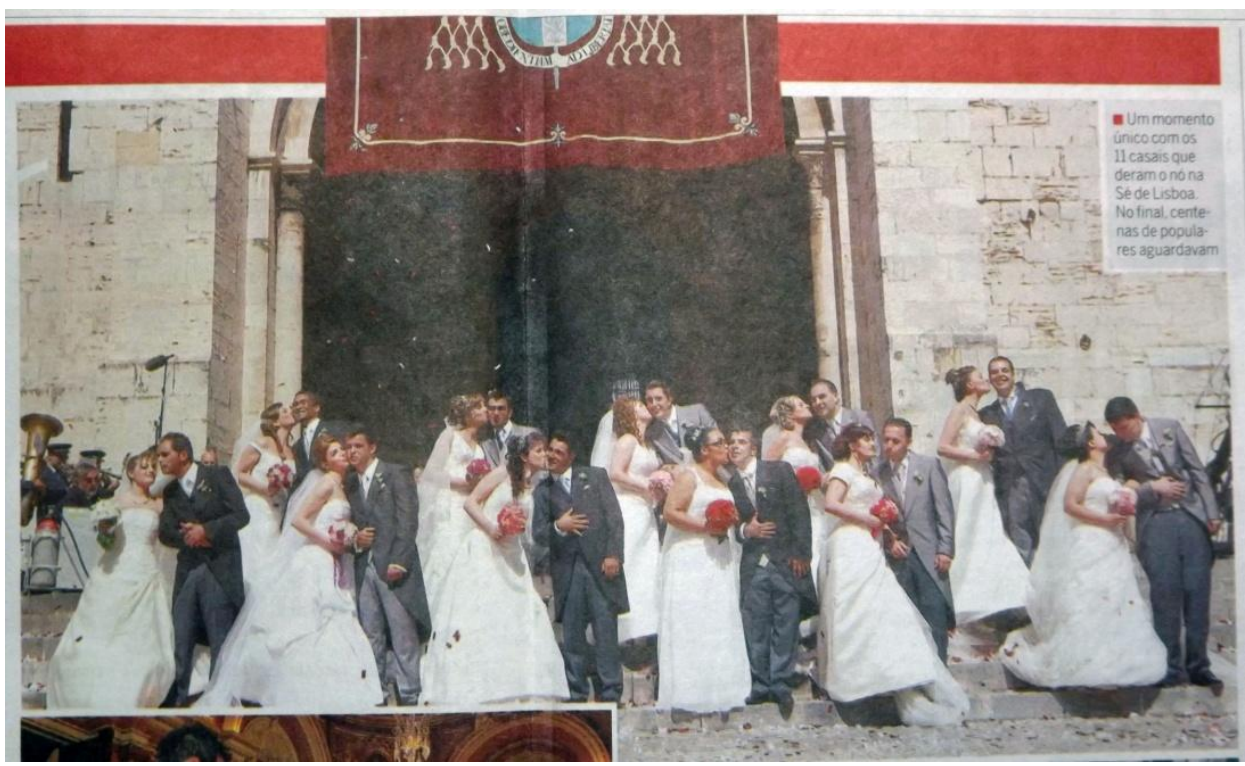

Fonte: Carvalho, 2012, p. 26.

O jornal Correio da Manhã dessa forma aproxima-se dos seus leitores ao trazer um evento popular e típico da cultura local. Ao se olhar essa marca cultural, dentro das 
origens pagãs das celebrações em homenagem aos santos católicos do mês de junho (período relacionado ao solstício de verão no hemisfério norte), encontra-se a celebração da fertilidade com um grande número de jovens casando-se, e dos quais esperam-se pelos filhos para perpetuar a cultura e a tradição locais. Outro ponto não enquadrado nesta imagem é a saída dos casais em cortejo em carro aberto e centenas de pessoas os saúdam como reis e rainhas como um elemento de alegria pela renovação daquela fertilidade vinda com a força do sol nos cultos pagãos e ao mesmo tempo católico com a devoção ao santo conterrâneo popular por unir casais em Portugal.

No dia 13 de junho de 2012, o jornal Correio da Manhã publicou a imagem 4, a qual traz uma das marcas culturais mais típicas das festas em Lisboa, as sardinhas.

Imagem 4: "Sardinha assada atrai centenas ao bairro de Alfama" (Nogueira, 2012, p. 27).

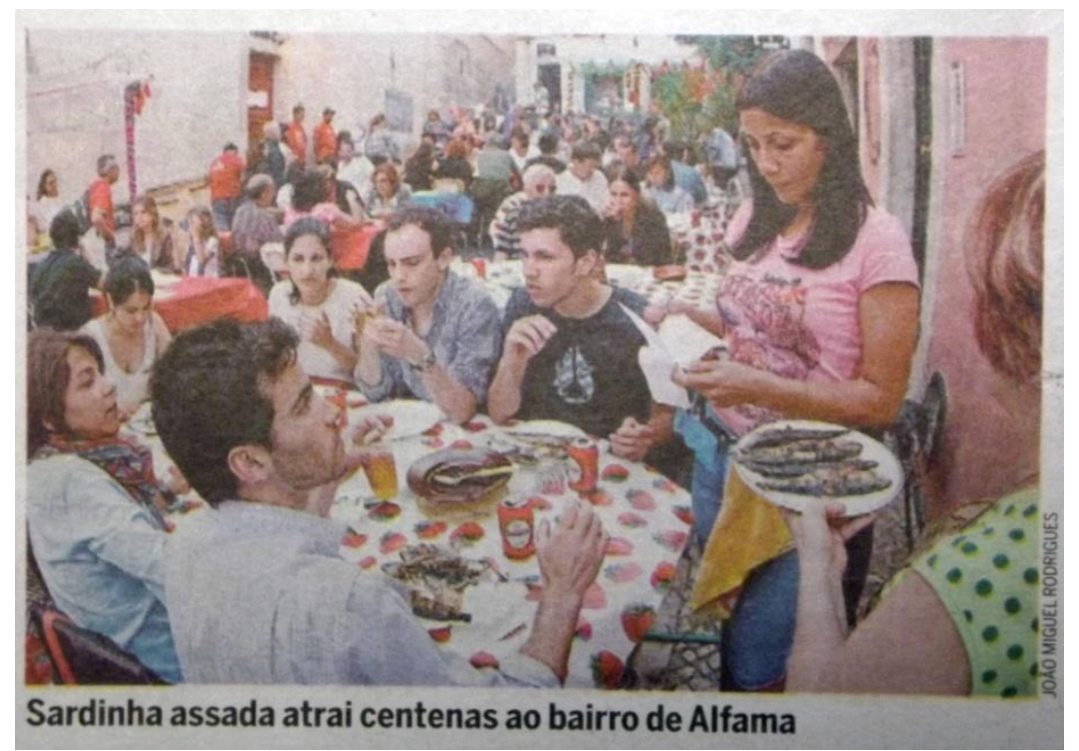

Fonte: Nogueira, 2012, p. 27.

As sardinhas fazem parte da culinária da festa do mês de junho em todo Portugal. São marcas da fartura da atividade econômica da pesca naquele ano e, ao mesmo tempo, são a alegria de uma festa, pois enche a mesa, sendo servida acompanhada de pimentões, pão e bebida a gosto. Lucena Filho (2012, p. 107) relata que

a sardinha é sempre presente em qualquer festa popular, citadina ou na província, dos Santos Populares ou nas romarias, à mesa ou à mão sobre uma boa fatia de pão com gordura a pingar. [...] A sardinha assada é popularmente denominada a rainha da festa, e consumida nas noites dos Santos Populares. Faz parte da ementa dos estabelecimentos gastronômicos e nos hotéis são oferecidas aos turistas acompanhadas de caldo verde, broa e um bom tinto.

Ao se direcionar o olhar para a imagem 4, pode-se observar que estas marcas estão presentes no enquadramento em plano geral de pessoas, em uma mesa farta em 
primeiro plano, com convidados e amigos ou familiares, em um momento de descontração, em uma rua lisboeta transformada em um grande banquete ao ar livre. Em segundo plano, observa-se a estação do ano: pleno verão (a ver pelos trajes utilizados) e se nota uma grande movimentação em torno do local de lisboetas e turistas.

Na imagem 5, em cores, vê-se a marca cultural maior de toda a festa de Lisboa, as Marchas Populares.

Imagem 5: "De regresso à competição, a marcha mostrou barcos, figurinos verdes e vermelhos, e evocou o mito de Ulisses e a fundação de Lisboa" (Carvalho, 2012, p. 27).

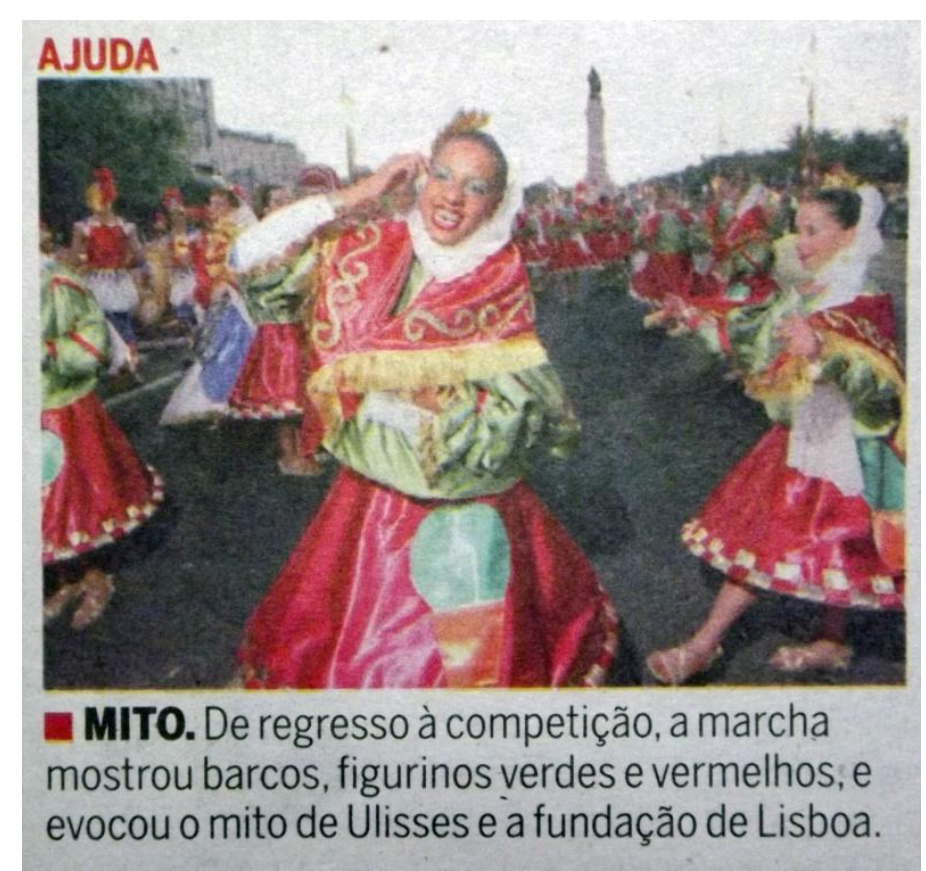

Fonte: Carvalho, 2012, p. 27.

As Marchas Populares são elementos da cultura de Lisboa as quais remontam uma antiga tradição de lavar os rostos nas bicas dos logradouros públicos durante a madrugada das noites de verão, em que os participantes saiam pelas ruas para despertar para o novo dia a mais de folia, após uma longa noite de festa. Atualmente, elas são realizadas por comunidades organizadas de cada um dos bairros e freguesias populares de Lisboa, um trabalho em conjunto que revela união. Nas noites de 12 e 13 de junho, em alegorias, os participantes descem a Avenida da Liberdade (antigo limite da cidade entre mouros e cristãos) até a praça dos Restauradores (Abel, 2006). As Marchas Populares, na visão de Lucena Filho (2012, p. 61): 
(...) que constituem o ponto alto dos festejos, são um evento aglutinador de centenas de pessoas, forças vivas da cidade constituídas pelas coletividades, marchantes, ensaiadores, coreógrafos, figurinistas, músicos e as estrelas anônimas dos bairros que, na sua dedicação e empenho permitem a continuidade deste acontecimento cultural popular. Trata-se enfim, de um conjunto de pessoas unidas pelo seu amor ao bairro onde vivem e o que cada Marcha representa.

Na imagem 5, o mito popular de que a cidade teria sido fundada pelo lendário Ulisses é o tema da Marcha da freguesia da Ajuda (um bairro popular da capital portuguesa).

A imagem 5 enquadrada, no primeiro plano, em plano americano, uma participante daquela marcha e, em segundo, os demais componentes. A escolha de um ângulo normal para tomada do retrato aproxima em pé de igualdade o interpretante e a representação visual, dando um aspecto de que o observador desfila com a marcha. A perspectiva da imagem traz a dimensão da festa local e o tamanho da marcha que desce a Avenida da Liberdade. A imagem simboliza o valor dado esta tradição nascida no âmbito popular, nas ruas da cidade do fado em uma forma única de se manifestar e dar sentido a vida de seus habitantes.

\section{Considerações finais}

Constata-se que, apesar de reportar sobre essas manifestações e representações da cultura popular, a fotografia jornalística dos periódicos escolhidos para análise resgata parcialmente o sentido daquela cultura popular. Sendo assim, a partir da discussão trazida com a metodologia e a teoria abordadas sobre a fotografia jornalística, a investigação buscou desvendar o que não ficou dito pelo retrato impresso nos jornais. A cultura popular foi retratada em uma superficialidade, com um aparente propósito de comercialização de edições daqueles jornais, não oferecendo ao leitor os sentidos e os significados mais apurados sobre tais manifestações culturais. Evidenciamos como importantes as contribuições da estratégia metodológica Fotocartografia Sociocultural e da teoria da Folkcomunicação, tendo em vista serem dois campos do conhecimento originalmente brasileiros com expansão para outras regiões além do Brasil.

Há uma marca da cultura popular nos jornais Tribuna do Norte e Correio da Manhã, entretanto trata-se de um ponto de vista hegemônico, ou seja, trazendo aquele tema como um conhecimento menor, não-válido, exótico, de uma aparente sociedade distante, com estética de cartão postal, quando na verdade, é parte da mesma sociedade cujos jornais estão inseridos. Observa-se que da cultura popular é construída uma imagem a qual não põe aquela tradição como um conhecimento válido, quando não 
discute o significado daquelas marcas dentro do contexto da cultura popular, mas sob os aspectos do espetáculo, do evento dentro do cenário turístico e econômico.

\section{Referências bibliográficas}

Abel, Marília (2006). As Marchas Populares: Pesquisa sobre as Origens. Lisboa: Sete Caminhos.

BRASIL.(2012) IBGE, Instituto Brasileiro de Geografia e Estatística. Censo 2010. Disponível em: <http://www.ibge.gov.br>. Acesso em: 22 maio 2012.

Carvalho, Débora. (2012) Noivos juram amor eterno. Correio da Manhã, Lisboa, 13 jun. 2012. Caderno Especial, p. 26-27.

Cascudo, Luís da Câmara. (2000) Dicionário do folclore brasileiro. 9 ed. São Paulo: Global, 2000.

Cascudo, Luís da Câmara. (1985) Superstição no Brasil. Belo Horizonte: Ed. Itatiaia; São Paulo: Ed. da Universidade de São Paulo.

Flusser, Vilém. (s.d.). Como ler sintomas. Berlim. Manuscrito não publicado, Arquivo Vilém Flusser.

Lucena Filho, Severino Alves de. (2012) Festa junina em Portugal: marcas culturais no contexto de folkmarketing. João Pessoa: Editora da UFPB.

Nobre, Itamar de Morais. (2011) Revelando os modos de vida da Ponta do Tubarão: a fotocartografia sociocultural como proposta metodológica. Natal: EDUFRN.

Nogueira, Joana. (2012) Sardinha no pão por 1,5 euros. Correio da Manhã, Lisboa, 13 jun. 2012. Caderno Especial, p. 27.

Peirce, Charles Sanders. (1931-1958). Collected Papers. Vol. I-VIII. Cambridge: Harvard University Press.

Santo. (2012) Tribuna do Norte, Natal, 10 jun. 2012. Capa.

Vivane, Gladis. (2012) Arraial com as bênçãos de São João. Tribuna do Norte, Natal, 22 jun. 2012. Caderno Fim de Semana, p. 06-07.

Élmano Ricarte de Azevêdo Souza é Graduado em Comunicação Social - habilitação em Jornalismo pela Universidade Federal do Rio Grande do Norte - UFRN, com graduação sanduíche na Universidade Católica Portuguesa em Lisboa, e mestrando na linha de Pesquisa de Produção de Sentido do Programa de Pós-graduação de Estudos da Mídia da UFRN. Integrante do Grupo de Estudos BOA-VENTURA - CCHLA/UFRN, em convênio com a Universidade de Coimbra-Portugal. Pesquisador do Grupo de Pesquisa PRAGMA - Pragmática da Comunicação e da Mídia. Membro da REDE FOLKCOM - Rede de Estudos e Pesquisa em Folkcomunicação.

ricarteazevedo@gmail.com

Itamar de Morais Nobre é docente e pesquisador do Departamento de Comunicação Social e do Programa de Pós-Graduação em Estudos da Mídia (PPgEM), da Universidade Federal do Rio Grande do Norte - UFRN. Mestre e Doutor em Ciências Sociais pelo Programa de Pós-Graduação em Ciências Sociais da UFRN. Pesquisador do Grupo de Pesquisa PRAGMA - Pragmática da Comunicação e da Mídia: teorias, 
linguagens, indústria cultural e cidadania. Integrante do Grupo de Estudos BOAVENTURA - CCHLA/UFRN, em convênio com a Universidade de Coimbra-Portugal. Membro do Núcleo de Pesquisa: Fotografia, da INTERCOM - Sociedade Brasileira de Estudos Interdisciplinares da Comunicação. Membro da REDE FOLKCOM - Rede de Estudos e Pesquisa em Folkcomunicação.

itanobre@gmail.com

Esta pesquisa contou com o apoio da Coordenação de Aperfeiçoamento de Pessoal de Nível Superior - CAPES. 